\title{
Produção de mudas de tomateiro por meio de estacas enraizadas em hidroponia
}

\author{
Adriano Alves Fernandes ${ }^{(1)}$, Herminia Emilia Prieto Martinez $z^{(1)}$, Derly José Henriques da Silva ${ }^{(1)}$ e José Geraldo Barbosa ${ }^{(1)}$
}

(1)Universidade Federal de Viçosa, Dep. de Fitotecnia, Av. P. H. Rolfs s/n CEP 36571-000 Viçosa, MG E-mail: afer03@ ig.com.br, herminia@ufv.br, derly@ufv.br, jgeraldo@ufv.br

\begin{abstract}
Resumo - O objetivo deste trabalho foi desenvolver um método de produção de mudas de tomateiro a partir de estacas laterais enraizadas em hidroponia. Foram realizados três experimentos. Nos experimentos 1 e 2, as estacas foram enraizadas em espuma fenólica e em solução nutritiva, respectivamente, e os tratamentos representaram as posições de retirada das estacas das axilas das folhas de 1 a 5 da base para o ápice. No experimento 3, estacas enraizadas nos experimentos 1 e 2, foram transplantadas para vasos contendo solução nutritiva e cultivadas até a produção do primeiro cacho. Com relação à massa de matéria fresca das raízes, pontos de interseção da raiz, massa de matéria seca dos caules e das folhas, comprimento de raízes, área foliar, número de folhas e diâmetro do caule, nos experimentos 1 e 2, não foi observada diferença estatística significativa entre os tratamentos 1, 2, 3 e 4. No experimento 3, apenas o diâmetro dos frutos apresentou diferença estatística entre os tratamentos. O tratamento 3 foi superior ao 5, e os tratamentos 1, 2, 3 e 4 foram semelhantes entre si. Em sistema hidropônico, podem ser produzidas mudas de tomate a partir de estacas, utilizando-se espuma fenólica ou solução nutritiva como meio de enraizamento.
\end{abstract}

Termos para indexação: Lycopersicon esculentum, propagação vegetativa, solução nutritiva, cultivo sem solo.

\section{Tomato seedling production through rooted cuttings in hydroponic}

\begin{abstract}
The objective of this work was to develop a method to produce tomato seedlings through rooted cuttings in hydroponic. Three experiments were carried out and in the experiments 1 and 2, the cuttings were rooted in fenolic foam and in nutritive solution, respectively. The treatments represented the cut positions of the cuttings in the axil of leaves 1 to 5 , from the base to the apex. In the experiment 3 , cuttings rooted in the experiments 1 and 2 were transplanted to vases containing nutritive solution and cultivated until the production of a single truss. The root fresh matter, root intersection, stem dry matter, leaf dry matter, root length, leaf area, leaf number and stem diameter, in the experiments 1 and 2, showed no significant differences between the treatments 1,2,3 and 4. In the experiment 3 , fruit diameter presented significant difference between the treatments. Treatment 3 was superior to treatment 5, and the treatments 1,2,3 and 4 were similar. In hydroponic, it is possible to produce tomato seedlings through cuttings rooted in fenolic foam or nutritive solution.
\end{abstract}

Index terms: Lycopersicon esculentum, vegetative propagation, nutrient solution, soiless culture .

\section{Introdução}

Entre as hortaliças de frutos, o tomate é a que mais desperta o interesse dos hidroponicultores, principalmente pelos preços competitivos e por sua aceitação no mercado. Os híbridos caqui, cereja e longa-vida são os de maior destaque (Moraes \& Furlani, 1999). O uso de sementes melhoradas e de boa procedência é importante no sucesso do empreendimento, porém, o seu alto preço, que pode chegar a cem dólares por mil sementes no caso do híbrido longa-vida, eleva o custo da produção.
Uma alternativa para diminuir o custo de produção é o uso de propagação assexuada na produção de mudas do tomateiro. Fernandes et al. (2002), trabalhando com tomate com um cacho em hidroponia, observaram o potencial vegetativo da cultura e constataram a ocorrência de grande número de brotações.

A propagação assexuada consiste na reprodução de indivíduos a partir de partes vegetativas das plantas, caracterizando-se principalmente por manter inalterada a constituição genética do clone durante as sucessivas gerações. Segundo Foster (1993), a propagação 
vegetativa é comum em muitas espécies comercialmente importantes, sendo a tecnologia de enraizamento de estacas o procedimento mais econômico na propagação em grande escala.

O método mais utilizado e difundido para produção de mudas de tomate é por meio de sementes, sendo o enraizamento de estacas pouco comum.

O objetivo deste trabalho foi desenvolver um método de produção de mudas de tomate a partir de estacas laterais enraizadas em hidroponia.

\section{Material e Métodos}

Foram realizados três experimentos em casa de vegetação da Universidade Federal de Viçosa, Viçosa, MG. Foi avaliada a produção de mudas de tomate híbrido Carmen em estacas retiradas de diferentes posições na planta-mãe. Para a coleta das estacas, as plantas matrizes foram produzidas pelas semeaduras escalonadas em intervalo de sete dias, durante cinco semanas, em bandejas de poliestireno de 72 células, ocupando-se células alternadas. O substrato utilizado foi a base de húmus de minhoca. Do $1^{\mathrm{o}}$ ao $10^{\circ} \mathrm{o}$ dia, após a semeadura, as mudas foram irrigadas com água deionizada. A partir do $10^{\circ}$ dia, foram irrigadas com solução nutritiva conforme Fernandes et al. (2002) com 50\% de força iônica. Todas as irrigações foram ministradas uma vez ao dia após as 18 horas em volume suficiente para saturar o substrato.

Quando as plantas da quinta e da primeira semeadura atingiram os estádios de primeira (21 dias após a semeadura, DAS) e quinta folha definitiva (49 DAS), respectivamente, foi realizada poda apical em todas as plantas, visando estimular a brotação da gema axilar imediatamente inferior ao ponto de poda. As demais brotações que surgiram nesse período foram eliminadas. Após a poda apical, as plantas da primeira, segunda, terceira, quarta e quinta semeadura continham cinco, quatro, três, duas e uma folhas, respectivamente.

No momento em que as brotações das gemas axilares apresentaram os valores médios de quatro folhas, 7,5 cm de altura e 4,79 $\mathrm{mm}$ de diâmetro (11 dias após a poda), foram coletadas com estilete, e transferidas para enraizamento, dando origem aos experimentos 1 e 2 . A primeira parte das estacas (experimento 1) foi colocada para enraizamento em bandejas de plástico contendo blocos de espuma fenólica de 5,0x5,0x3,8 cm. Essas estacas foram irrigadas uma vez ao dia com solução nutritiva de crescimento vegetativo (Fernandes et al.,
2002) com $50 \%$ de força iônica. A irrigação era efetuada até a saturação da espuma. Cada parcela continha cinco plantas em cada bandeja. Construiu-se, sobre a bancada, uma câmara de plástico transparente para minimizar as perdas de água por evapotranspiração. A segunda parte das estacas (experimento 2) foi colocada para enraizamento diretamente em solução nutritiva de crescimento vegetativo aerada (Fernandes et al., 2002) com 50\% de força iônica. Foram utilizados vasos de oito litros, representando, cada vaso, uma parcela, composta por cinco plantas.

Aos 19 dias após a transferência para enraizamento (DATE), foram retiradas quatro plantas por parcela para a avaliação da altura, do diâmetro do caule, do número de folhas, da área foliar e massa de matéria seca das folhas e do caule. Na avaliação das raízes, no primeiro experimento, foi retirada e pesada toda raiz que se encontrava fora do bloco de espuma fenólica. Posteriormente, foram feitos dois cortes verticais nas espumas, reduzindo o bloco a $5 \times 5 \times 1 \mathrm{~cm}$. Foram contados os pontos de interseção da raiz nas duas faces de $5 \times 5 \mathrm{~cm}$, totalizando a densidade de pontos por $50 \mathrm{~cm}^{2}$. No segundo experimento, o comprimento do sistema radicial foi medido pelo método de Tennant (1975).

Os tratamentos $1,2,3$, 4 e 5 representaram as posições de retirada das estacas das folhas 1, 2, 3, 4 e 5, respectivamente, e foram iguais nos experimentos $1 \mathrm{e}$ 2 , que foram conduzidos no delineamento de blocos ao acaso com três repetições. Os dados foram submetidos à análise de variância e as médias comparadas pelo teste de Tukey a 5\% de probabilidade. Posteriormente foi realizada a análise conjunta dos experimentos.

Uma planta de cada parcela dos experimentos 1 e 2 foi transplantada para vaso de $9 \mathrm{~L}$ com solução nutritiva de crescimento vegetativo (Fernandes et al., 2002), compondo o terceiro experimento, que foi conduzido em delineamento inteiramente casualizado com arranjo fatorial $2 \times 5$. O primeiro fator foi representado pelo meio de enraizamento, espuma fenólica ou solução nutritiva, e o segundo fator, pelas cinco posições de retirada das estacas, perfazendo dez tratamentos com três repetições, totalizando 30 vasos. Os vasos foram arranjados com espaços de $0,40 \mathrm{~m}$ entre plantas e $0,70 \mathrm{~m}$ entre linhas.

As plantas foram conduzidas com um cacho de no máximo seis frutos, e a poda apical foi realizada aos sete dias após o transplante (DAT), conservando-se duas 
folhas acima do primeiro cacho. Durante a fase experimental, foram feitas podas periódicas para manutenção do número de frutos e folhas preconizados. Com o aparecimento dos cachos, foi trocada a solução de crescimento vegetativo pela solução de frutificação (Fernandes et al., 2002).

$\mathrm{O} \mathrm{pH}$ das soluções nutritivas foi ajustado à faixa de 5,5 a 6,5 utilizando-se $\mathrm{HCl}$ ou $\mathrm{NaOH}$ (Martinez, 2002). Na reposição dos nutrientes, foi considerada a depleção máxima de 30\%, com base na redução da condutividade elétrica inicial. As reposições de água foram realizadas com água deionizada, admitindo-se uma redução máxima em torno de $40 \%$ do volume do vaso.

Após a colheita (60 a 82 DAT), foi quantificada a produção média por planta, massa média dos frutos e número de frutos. Avaliaram-se nos dois primeiros frutos colhidos de cada parcela, diâmetro, espessura do pericarpo e sólidos solúveis totais na polpa e pericarpo. Posteriormente, os frutos foram classificados de acordo com a portaria do Ministério da Agricultura e Reforma Agrária: gigante, com maior diâmetro transversal $($ MDT $)>100 \mathrm{~mm}$; grande, com MDT entre $80 \mathrm{e}$ $100 \mathrm{~mm}$; médio, com MDT entre 65 e $80 \mathrm{~mm}$ e pequeno, com MDT entre 50 e 65 mm (Fontes \& Silva, 2002).

Os dados foram submetidos à análise de variância e as médias comparadas pelo teste de Tukey a 5\% de probabilidade.

\section{Resultados e Discussão}

No primeiro experimento, em espuma fenólica, o enraizamento das estacas tornou-se perceptível com a visualização das raízes na parte externa dos blocos aos dez dias após a transferência para enraizamento (DATE). A porcentagem de enraizamento aos 19 DATE foi de $98,67 \%$, semelhante ao encontrado por Gûl et al. (1994) em estacas de tomate tratadas com hormônios e enraizadas em perlita, avaliadas aos 21 DATE.

Não houve diferença significativa em relação à massa de matéria fresca das raízes, pontos de interseção da raiz, número de folhas, e diâmetro do caule. Quanto aos valores de massa de matéria seca do caule e das folhas, os tratamentos 3 e 2 foram semelhantes aos tratamentos 4 e 1 e superiores ao tratamento 5. Quanto à área foliar e altura, o tratamento 2 foi semelhante aos tratamentos 3,1 e 4 e superior ao tratamento 5 (Tabela 1).

Nesse experimento, foi observada murcha das estacas, sendo necessárias algumas substituições. Kraus \& Kraybil (1918), citados por Hartmann \& Kester (1990), observaram que estacas de tomate com altas concentrações de nitrogênio e baixas concentrações de carboidratos apodreceram sem formar raízes. Fachinello et al. (1995) consideram que a condição nutricional da planta matriz pode afetar o enraizamento das estacas.

Tabela 1. Características do tomateiro, híbrido Carmen, provenientes de estacas da primeira folha (1), da segunda folha (2), da terceira folha (3), da quarta folha (4) e da quinta folha (5) enraizadas em espuma fenólica ou solução nutritiva ${ }^{(1)}$.

\begin{tabular}{|c|c|c|c|c|c|c|}
\hline \multirow[t]{2}{*}{ Característica } & \multicolumn{5}{|c|}{ Tratamentos } & \multirow[t]{2}{*}{$\mathrm{CV}(\%)$} \\
\hline & 1 & 2 & 3 & 4 & 5 & \\
\hline & \multicolumn{5}{|c|}{ Espuma fenólica } & \\
\hline Matéria fresca das raízes (g) & $1,05 \mathrm{~A}$ & $1,77 \mathrm{~A}$ & $1,70 \mathrm{~A}$ & $1,74 \mathrm{~A}$ & $0,97 \mathrm{~A}$ & 23,81 \\
\hline Pontos de interseção das raízes & $86,53 \mathrm{~A}$ & $84,92 \mathrm{~A}$ & $70,00 \mathrm{~A}$ & $40,92 \mathrm{~A}$ & $65,92 \mathrm{~A}$ & 30,28 \\
\hline Matéria seca dos caules (g) & $0,24 \mathrm{AB}$ & $0,34 \mathrm{~A}$ & $0,34 \mathrm{~A}$ & $0,26 \mathrm{AB}$ & $0,17 \mathrm{~B}$ & 18,76 \\
\hline Matéria seca das folhas (g) & $0,29 \mathrm{AB}$ & $0,37 \mathrm{~A}$ & $0,38 \mathrm{~A}$ & $0,31 \mathrm{AB}$ & $0,22 \mathrm{~B}$ & 14,58 \\
\hline Área foliar $\left(\mathrm{cm}^{2}\right)$ & $139,16 \mathrm{AB}$ & $168,38 \mathrm{~A}$ & $150,48 \mathrm{AB}$ & $133,58 \mathrm{AB}$ & $95,34 \mathrm{~B}$ & 14,24 \\
\hline Altura $(\mathrm{cm})$ & $14,16 \mathrm{AB}$ & $15,61 \mathrm{~A}$ & $13,87 \mathrm{AB}$ & $12,96 \mathrm{AB}$ & $11,13 \mathrm{~B}$ & 10,19 \\
\hline Número de folhas & $5,83 \mathrm{~A}$ & $5,53 \mathrm{~A}$ & $5,67 \mathrm{~A}$ & $5,27 \mathrm{~A}$ & $5,13 \mathrm{~A}$ & 6,23 \\
\hline \multirow[t]{2}{*}{ Diâmetro dos caules (mm) } & $5,15 \mathrm{~A}$ & $5,73 \mathrm{~A}$ & $5,87 \mathrm{~A}$ & $5,47 \mathrm{~A}$ & $5,13 \mathrm{~A}$ & 6,96 \\
\hline & \multicolumn{5}{|c|}{ Solução nutritiva } & \\
\hline Comprimento das raízes $(\mathrm{cm})$ & $21,06 \mathrm{~A}$ & $27,75 \mathrm{~A}$ & $22,77 \mathrm{~A}$ & $23,42 \mathrm{~A}$ & $16,67 \mathrm{~A}$ & 27,67 \\
\hline Matéria seca dos caules (g) & $0,51 \mathrm{AB}$ & $0,76 \mathrm{~A}$ & $0,55 \mathrm{AB}$ & $0,58 \mathrm{AB}$ & $0,25 \mathrm{~B}$ & 23,78 \\
\hline Matéria seca das folhas (g) & $0,72 \mathrm{AB}$ & $0,94 \mathrm{~A}$ & $0,83 \mathrm{AB}$ & $0,78 \mathrm{AB}$ & $0,41 \mathrm{~B}$ & 20,94 \\
\hline Área foliar $\left(\mathrm{cm}^{2}\right)$ & $372,64 \mathrm{AB}$ & $476,97 \mathrm{~A}$ & $429,57 \mathrm{~A}$ & $404,07 \mathrm{~A}$ & $192,10 \mathrm{~B}$ & 19,14 \\
\hline Altura $(\mathrm{cm})$ & $15,43 \mathrm{BC}$ & $22,98 \mathrm{~A}$ & $16,35 \mathrm{BC}$ & $19,23 \mathrm{AB}$ & $12,18 \mathrm{C}$ & 12,58 \\
\hline Número de folhas & $6,60 \mathrm{AB}$ & $7,63 \mathrm{~A}$ & $6,47 \mathrm{AB}$ & $6,20 \mathrm{AB}$ & $5,45 \mathrm{~B}$ & 9,98 \\
\hline Diâmetro dos caules (mm) & $5,93 \mathrm{AB}$ & $6,98 \mathrm{~A}$ & $6,67 \mathrm{AB}$ & $7,33 \mathrm{~A}$ & $5,10 \mathrm{~B}$ & 10,23 \\
\hline
\end{tabular}

${ }^{(1)}$ Em cada linha, as médias seguidas da mesma letra não diferem entre si a $5 \%$ de probabilidade pelo teste de Tukey. 
Com relação ao teor de carboidratos, tem-se observado que reservas mais abundantes correlacionam-se com maiores porcentagens de enraizamento e sobrevivência das estacas. A formação de raízes em estacas de videira apresetaram correlação significativa com o teor de amido, sendo o porcentual de enraizamento de $63 \%$ nas mais ricas, $35 \%$ nas intermediárias e $17 \%$ naquelas com menor concentração.

No segundo experimento, em solução nutritiva, o enraizamento tornou-se perceptível com a visualização de algumas raízes e calos na parte basal das estacas aos 4 DATE. A porcentagem de enraizamento aos 19 DATE foi de $96 \%$. Aos quatro dias de contato com a solução nutritiva aerada, as estacas de tomate apresentaram pequenas raízes, demostrando grande facilidade para expressar o seu potencial organogênico.

Com base nos dados obtidos, admite-se que, nas estacas de tomateiro, o nível interno de hormônios e substâncias relacionadas ao enraizamento é suficiente para permitir a propagação vegetativa dessa cultura sem aplicação de reguladores de crescimento. Gûl et al. (1994), estudando a estaquia do tomateiro, demostraram que a aplicação de $1.000 \mathrm{mg} \mathrm{L}^{-1}$ de ácido indolbutírico reduziu o crescimento do caule e da raiz. Por sua vez, a dose de $500 \mathrm{mg} \mathrm{L}^{-1}$ de AIB aumentou o diâmetro e a massa de matéria seca do caule, mas impediu a formação e elongação de raízes. Já o uso de solução com concentração de $1.000 \mathrm{mg} \mathrm{L}^{-1}$ de ácido indolacético aumentou o crescimento das mudas e de suas raízes em relação ao controle que se constituía apenas da imersão em água.

A formação inicial de raízes predominantemente seguiu em linha vertical em laterais opostas das estacas do tomateiro. Segundo Hartmann \& Kester (1990), o local de emissão dos primórdios de raízes é bastante variável conforme a espécie e o tipo de estaca. Em plantas herbáceas, as raízes adventícias originamse entre os feixes vasculares e para fora destes e podem emergir em filas, acompanhando os feixes vasculares, mas os tecidos envolvidos no sítio de origem variam bastante, segundo a espécie. Por exemplo, em tomateiro, as raízes adventícias se originam no parênquima do floema.

O comprimento da raiz foi a única característica que não apresentou diferença significativa entre os tratamentos, sendo obtidos o maior valor de $27,75 \mathrm{~cm}$ e o menor de $16,67 \mathrm{~cm}$ pelos tratamentos 2 e 5 , respectivamente (Tabela 1). Seniz (1994), trabalhando com mudas de tomateiro cv. ES 58, provenientes de sementes, avaliadas aos 21 dias após a semeadura (DAS), relatou comprimento máximo de $3,2 \mathrm{~cm}$. Aos $42 \mathrm{DAS}$, o autor observou comprimento máximo e mínimo de 22,3 e $12,9 \mathrm{~cm}$, respectivamente. Utilizando perlita mais fertilizante como substrato, Gul et al. (1994) obtiveram comprimento máximo de raiz de $23,7 \mathrm{~cm}$ para as estacas. Tanto Seniz (1994) quanto Gul et al. (1994) obtiveram maiores comprimentos de raízes utilizando substratos como turfa ou perlita, porém esses valores ficaram abaixo dos observados em solução nutritiva no experimento 2 .

Com relação à massa de matéria seca do caule, da folha, área foliar, número de folhas e diâmetro, o tratamento 2 não diferiu estatisticamente dos tratamentos 1 , 3 e 4 e foi superior ao tratamento cinco. Quanto à altu$\mathrm{ra}$, o tratamento 2 foi igual ao $4 \mathrm{e}$ superior aos demais, e o maior e o menor valor obtidos para essa característica foram 22,98 (tratamento 2) e 12,18 cm (tratamento 5), respectivamente.

$\mathrm{Na}$ análise conjunta dos experimentos, foram consideradas as características massa de matéria seca do caule, altura, número de folhas e diâmetro do caule, obtidas no primeiro e segundo experimentos. Quanto à massa de matéria seca do caule, número de folhas e diâmetro do caule, houve diferença significativa em relação ao meio de enraizamento, destacando-se o enraizamento em solução nutritiva como o mais adequado. A interação entre tratamentos e meios de enraizamento não foi significativa, indicando que o comportamento dos tratamentos independe dos meios.

Este resultado permite fazer recomendações gerais, ou seja, o melhor tratamento é indicado tanto para enraizamento em espuma fenólica quanto em solução nutritiva. Com relação à característica altura, houve diferença significativa entre os meios, destacando-se a solução nutritiva como a mais adequada. A interação entre tratamentos e meios foi significativa, ou seja, o comportamento dos tratamentos é influenciado pelo meio de enraizamento. Portanto, pode-se considerar os resultados obtidos nas análises individuais, isto é, não podem ser feitas recomendações gerais para essa característica, valendo apenas as conclusões para cada meio de enraizamento separado.

No terceiro experimento, na avaliação das características produção por planta, massa média do fruto e número de frutos, foram considerados todos os frutos, $\mathrm{o}$ que proporcionou coeficiente de variação elevado, visto que houve variação na formação de frutos cujo número oscilou entre 1 e 6 por planta. Porém, com relação às demais características, em que se considerou a avaliação apenas dos dois primeiros frutos colhidos, os coeficientes de variação foram mais baixos (Tabela 2). 
A produção por planta não apresentou diferença significativa. O valor de $853,77 \mathrm{~g}$ obtido aos 82 DAT, com as estacas da primeira posição no meio de enraizamento solução nutritiva (Tabela 2), é o que mais se aproxima do valor de 919,7 g por planta, obtido por Fernandes et al. (2002) aos 96 DAT, para plantas do híbrido Carmen originadas de sementes cultivadas com um cacho em hidroponia. Gul et al. (1994), trabalhando com plantas de tomate da cultivar Carpy, também provenientes de estacas, obtiveram $1.683 \mathrm{~g}$ por planta em um período de 86 dias, porém esse valor foi obtido com a produção de três cachos.

A massa média do fruto $(144,95 \mathrm{~g})$, obtida na segunda posição no meio espuma fenólica (Tabela 2), se aproxima da massa de 154,7 g encontrada por Fernandes et al. (2002). Com relação ao número de frutos por planta, não se observou diferença significativa entre os tratamentos. As médias variaram de 4,33 a 6,00 (Tabela 2).

$\mathrm{O}$ diâmetro de fruto foi a única característica avaliada no terceiro experimento que apresentou diferença significativa. Entre as posições de retirada das estacas no meio de enraizamento espuma fenólica, foi observado que as posições três e cinco apresentaram o maior
$(7,85 \mathrm{~cm})$ e o menor $(6,53 \mathrm{~cm})$ valor, respectivamente. Não houve diferença significativa entre posições de retirada das estacas quando se usou a solução nutritiva como meio de enraizamento. Entretanto, foi observada diferença significativa entre os meios de enraizamento dentro da posição cinco, apresentando os valores de $7,70 \mathrm{~cm}$ para solução nutritiva e $6,53 \mathrm{~cm}$ para espuma fenólica (Tabela 2). De acordo com a classificação do Ministério da Agricultura, foram obtidos 14,3\% de frutos grandes, $69,4 \%$ de frutos médios e $16,3 \%$ de frutos pequenos. O tamanho final do fruto é correlacionado com algumas características, incluindo o número de carpelos no ovário, o número de sementes, a posição do fruto, a sequiência de formação do fruto no cacho e as condições predominantes durante a fase de crescimento (Kinet \& Peet, 1997).

A posição e a seqüência de formação nos cachos são fatores críticos na determinação dessa característica. Usualmente frutos que se desenvolvem na posição proximal são maiores que os da posição distal. O tamanho final pode ser manipulado alterando-se a sequiência de formação. Se forem induzidos primeiro, os frutos distais tornam-se maiores que os proximais.

Tabela 2. Características dos frutos de tomateiro, híbrido Carmen, provenientes de estacas da primeira folha (1), da segunda folha (2), da terceira folha (3), da quarta folha (4) e da quinta folha (5) enraizadas em espuma fenólica ou solução nutritiva ${ }^{(1)}$.

\begin{tabular}{|c|c|c|c|c|c|c|}
\hline \multirow[t]{2}{*}{ Meio } & \multicolumn{5}{|c|}{ Tratamentos } & \multirow[t]{2}{*}{$\mathrm{CV}(\%)$} \\
\hline & 1 & 2 & 3 & 4 & 5 & \\
\hline \multicolumn{7}{|c|}{ Produção por planta $(\mathrm{g})^{(2)}$} \\
\hline Espuma fenólica & $428,51 \mathrm{Aa}$ & $580,41 \mathrm{Aa}$ & $709,56 \mathrm{Aa}$ & $639,19 \mathrm{Aa}$ & $420,72 \mathrm{Aa}$ & \multirow{2}{*}{25,7} \\
\hline Solução nutritiva & $853,77 \mathrm{Aa}$ & $611,99 \mathrm{Aa}$ & $521,58 \mathrm{Aa}$ & $571,10 \mathrm{Aa}$ & $846,69 \mathrm{Aa}$ & \\
\hline \multicolumn{7}{|c|}{ Massa dos frutos $(\mathrm{g})^{(2)}$} \\
\hline Espuma fenólica & $88,22 \mathrm{Aa}$ & $144,95 \mathrm{Aa}$ & $139,90 \mathrm{Aa}$ & $113,20 \mathrm{Aa}$ & $104,95 \mathrm{Aa}$ & \multirow{2}{*}{17,9} \\
\hline Solução nutritiva & $142,30 \mathrm{Aa}$ & $109,91 \mathrm{Aa}$ & $126,24 \mathrm{Aa}$ & $114,39 \mathrm{Aa}$ & $141,11 \mathrm{Aa}$ & \\
\hline \multicolumn{7}{|c|}{ Número de frutos por planta ${ }^{(2)}$} \\
\hline Espuma fenólica & $5,00 \mathrm{Aa}$ & 4,33Aa & $5,00 \mathrm{Aa}$ & $5,33 \mathrm{Aa}$ & $4,33 \mathrm{Aa}$ & \multirow{2}{*}{16,7} \\
\hline Solução nutritiva & $6,00 \mathrm{Aa}$ & $5,50 \mathrm{Aa}$ & 4,67Aa & $5,00 \mathrm{Aa}$ & $6,00 \mathrm{Aa}$ & \\
\hline \multicolumn{7}{|c|}{ Diâmetro de frutos $(\mathrm{mm})$} \\
\hline Espuma fenólica & 7,27ABa & $7,18 \mathrm{ABa}$ & $7,85 \mathrm{Aa}$ & $6,62 \mathrm{ABa}$ & $6,53 \mathrm{Bb}$ & \multirow{2}{*}{7,2} \\
\hline Solução nutritiva & $7,60 \mathrm{Aa}$ & $6,98 \mathrm{Aa}$ & $7,32 \mathrm{Aa}$ & 7,07Aa & $7,70 \mathrm{Aa}$ & \\
\hline \multicolumn{7}{|c|}{ Espessura do pericarpo $(\mathrm{mm})$} \\
\hline Espuma fenólica & $0,98 \mathrm{Aa}$ & $0,97 \mathrm{Aa}$ & $1,02 \mathrm{Aa}$ & $0,98 \mathrm{Aa}$ & $0,92 \mathrm{Aa}$ & \multirow{2}{*}{8,8} \\
\hline Solução nutritiva & $0,98 \mathrm{Aa}$ & $1,00 \mathrm{Aa}$ & $1,08 \mathrm{Aa}$ & $0,95 \mathrm{Aa}$ & $1,02 \mathrm{Aa}$ & \\
\hline \multicolumn{7}{|c|}{ Grau Brix da polpa (\%) } \\
\hline Espuma fenólica & $4,43 \mathrm{Aa}$ & $4,20 \mathrm{Aa}$ & $4,10 \mathrm{Aa}$ & $4,37 \mathrm{Aa}$ & $5,63 \mathrm{Aa}$ & \multirow{2}{*}{13,8} \\
\hline Solução nutritiva & $4,13 \mathrm{Aa}$ & $4,58 \mathrm{Aa}$ & 4,95Aa & $4,90 \mathrm{Aa}$ & 4,98Aa & \\
\hline \multicolumn{7}{|c|}{ Grau Brix do pericarpo (\%) } \\
\hline Espuma fenólica & $4,55 \mathrm{Aa}$ & $4,62 \mathrm{Aa}$ & $4,53 \mathrm{Aa}$ & 4,57Aa & $5,90 \mathrm{Aa}$ & \multirow{2}{*}{16,8} \\
\hline Solução nutritiva & 4,18Aa & $4,90 \mathrm{Aa}$ & $5,42 \mathrm{Aa}$ & $5,40 \mathrm{Aa}$ & $5,23 \mathrm{Aa}$ & \\
\hline
\end{tabular}

${ }^{(1)}$ Médias seguidas pela mesma letra, maiúscula nas linhas e minúscula nas colunas, não diferem entre si, a 5\% de probabilidade, pelo teste de Tukey. ${ }^{(2)}$ Dados originais; para análise estatística houve transformação em raiz quadrada de $\mathrm{x}+1$. 
Quando há indução simultânea de todos os frutos do mesmo cacho, eles terão tamanho final semelhante (Kinet \& Peet, 1997).

Quanto ao teor de sólidos solúveis, não foram observadas diferenças significativas, porém, de acordo com Morgan (1997), valores de grau Brix acima de cinco, para tomate, indicam frutos de alta qualidade. Altas quantidades de açúcares e ácidos são requeridas para um melhor paladar do fruto. Alto teor de ácido e baixo teor de açúcar podem resultar em um sabor cortante ou adstringente. Alto teor de açúcar e baixo teor de ácido resultam em sabor mais suave. Com baixos níveis de ácidos e açúcares o resultado é um fruto insípido (Grierson \& Kader, 1986).

\section{Conclusão}

A propagação vegetativa do tomateiro é viável, podendo-se empregar estacas oriundas de diferentes posições na planta matriz.

\section{Agradecimentos}

À Universidade Federal de Viçosa pela oportunidade de realização do trabalho; à Fapemig pelo auxílio financeiro; à Capes pela concessão da bolsa de pesquisa ao primeiro autor.

\section{Referências}

FACHINELLO, J.C.; HOFFMANN, A.; NACHTIGAL, J.C.; KERSTEN, E.; FORTES, G.R.L. Propagação de plantas frutíferas de clima temperado. 2.ed. Pelotas: UFPel, 1995. 178p.
FERNANDES, A.A.; MARTINEZ, H.E.P.; FONTES, P.C.R. Produtividade, qualidade dos frutos e estado nutricional do tomateiro tipo longa vida conduzido com um cacho, em cultivo hidropônico, em função das fontes de nutrientes. Horticultura Brasileira, v.20, p.564-570, 2002.

FONTES, P.C.R.; SILVA, D.J.H. Produção de tomate de mesa. Viçosa: Aprenda Fácil, 2002. 196p.

FOSTER, G.S. Selection and breeding for extreme genotypes. In: AHUJA, M.R.; LIBBY, W.J. (Ed.). Clonal forestry - I: genetics and biotechnology. Berlin: Springer, 1993. p.50-67.

GRIERSON, D.; KADER, A.A. Fruit ripening and quality. In: ATHERTON, J.G. The tomato crop: a scientific basis for improvement. London: Chapman and Hall, 1986. p.241-280.

GÛL, A.; TUZEL, Y.; YOLTAS, T. Possibilities of using side shoots as propagation material in greenhouse tomato production. Acta Horticulturae, n.366, p.271-278, 1994.

HARTMANN, H.T.; KESTER, D.E. Propagación de plantas: principios y practicas. 4.ed. México: Continental, 1990. 760p.

KINET, J.M.; PEET, M.M. Tomato. In: WIEN, H.C. (Ed.). The physiology of vegetable crops. Cambridge: Cambridge University Press, 1997. p.207-258.

MARTINEZ, H.E.P. O uso do cultivo hidropônico de plantas em pesquisa. 3.ed. Viçosa: Imprensa Universitária, 2002. 61p. (Cadernos Didáticos, 1).

MORAES, C.A.G.; FURLANI, P.R. Cultivo de hortaliças de frutos em hidroponia em ambiente protegido. Informe Agropecuário, v.20, p.105-113, 1999.

MORGAN, L. Hydroponic fruit quality testing. Pratical Hydroponics \& Greenhouses, n.34, p.21-31, 1997.

SENIZ, V. Seedling prodution in solanaceae crops. Acta Horticulturae, n.366, p.243-250, 1994.

TENNANT, D. A test of a modified line intersect method of estimating root length. Journal of Ecology, v.63, p.995-1001, 1975.

Recebido em 17 de outubro de 2003 e aprovado em 12 de janeiro de 2004 